tain that the principle is altogether erroneous, depending as it does on the assumption that the pressure of the atmosphere is purely a function of its specific gravity or density. This is not true, for pressure may vary within wide limits, whilst the density remains unchanged. Experimentally this might be shown by putting, say, an aneroid and a balance, such as I have been speaking of, in a large glass vessel, which can be made air-tight when closed. Under normal conditions the two will at first register the same pressure; but if the temperature is sufficiently increased or diminished, the increase or diminution of elastic force will manifest itself by the aneroid; but as the density remains unaltered, the balance will show no change. Does such an experiment at all correspond with any natural observations? I think so, in, of course, a limited degree. If the lower part of a column of air is heated, its expansive force will push the adjacent air outwrards and upwards; but as it docs so, it has to overcome a certain amount of inertia; to do this requires time, during which, as the volume of the heated air does not increase in proportion to the temperature, the elastic force does. This ought to be shown by the barometer; I think it often is, but the barometer is a sluggish instrument at best, and its indications are undoubtedly wanting in quickness, and therefore in exactness. Still its principle is correct ; so is the principle of the aneroid, or of Bourdon's barometer (on which there is an interesting paper in the Quartcrly. Fournal of the Meteorological Society for April 1872), though practical difficulties stand in the way of their use becoming general. But the tangent balance is not capable of measuring atmospheric tension, except when that tension depends on density alone; and this is frequently not the case-perhaps never. April 23

\section{Acquired Habits in Plants}

$\Lambda \mathrm{r}$ p. 446 of NATURE, J. G. records a "dog violet" which he thinks has assumed an unusual form. As there are several plants called "dog violet," and as one of them does in favourable situations attain a very considerable height, it would be interesting to know what was the species observed by the river Aled. The Viola canina ( $V$. riviniana Reich.), in one of its forms which is probably a distinct species, has flowering shoots which sometimes attain a foot in length, and if supported by the surrounding vegetation do sometimes stand nearly upright, If this was the plant observed, J. G. only found a more than usually strong form.

$$
\text { C. C. Babington }
$$

\section{The Zodiacal Light}

MR. BACKHouse asks if the observations given-in vol. iii. p. 203 , afford any proof that the Zodiacal Light is not a lens. shaped disc of light enveloping the Sun; if this theory were correct, and the sun enveloped in a continuous mass of lightreflecting matter, whenever the light is seen in the evening after sunset, it ought to be also seen in the morning before sun. rise, of the same brilliancy at the same angular distances from the sun, especially when those distances are small, for then the effect of an elliptical form in the section of the envelope by the plane of the ecliptic would be almost entirely eliminated.

The results of observation given in most of our hand-books of astronomy are therefore directly at variance with this theory, and I did not consider it necessary to allude to it before.

Jamaica, April 6

Maxwell Hall

\section{ON VENOMIOUS CATERPILLARS*}

\section{Por}

ISON and renom are often used as convertible terms. I do not understand them to be so. Poison properly means something which injures the system by introduction through the stomach. Venom, something which injures by introduction into the vascular system through lesion of the tissues. Most poisons are also venoms; whatever injures, if introduced into the stomach, will most probably also injure if introduced directly into the blood. But the converse is not true : most venoms are not poisons, that is, it is not by digestion and assimilation that they work, but by entering the vascular system from without. It is said that you may swallow the venom of the rattlesnake with impunity; and I imagine you may, if it does get absorbed through the mucous membrane; but Dr. Fayrer's experience, lately published, of the effects

* A paper read at the opening of the Kensington Entomological Society. of the semi-swallowing; which occurs in extracting the venom from a poisoned wound by sucking, would rather scem to show that such extremely virulent venom would penetrate the mucous membrane, and act as if actually introduced by a wound, his throat having become dangerously ulcerated from sucking the poison from the wound of a man bitten by a cobra. There is yet another way than swallowing or being wounded, by which venom may injure, and that is through the nervous system, by application to the skin. This is the way in which the nettle must sting. In that case there is not the smallest lesion in the skin, and if a nettle were artistically made to touch the open surface of a gaping wound, it would not sting at all ; neither is it by mechanical irritation that the pain is caused. The nettle has a venom gland, as well as the rattlesnake, and it is the application of this venom to the delicate termination of the nerves in the skin which produced the pain felt.

The subject to which I invite the consideration of the Society this evening is whether any insects possess similar power of injury to that of the nettle. In ordinary cases the venom of insects is applied by a puncture in the skin, into which the venom is introduced by an appa. ratus provided for the purpose. But for a long time it has been said that certain caterpillars sting like the nettle, although the authorities have for the most part been too vague to allow us to be very sure as to the fact; and supposing the fact to be true, it has been argued that the pain or annoyance was merely the result of mechani. cal irritation of a similar nature to that which medical men sometimes meet with in hairdressers, or rather haitcutters, where minute portions of the cut hair of their customers work their way into the skin below the shirt-sleeve and give rise to a painful and irritating sore on the wrist. Two passages which I shall take leave to quote, will bring the question, as it at present stands, pretty fairly before the meeting. The first is from a paper by myself on the geographical relations of the chief Coleopterous Faunas, which was published in the Linnacan Society's Journal for 1870 (p. 55) :-

"A very remarkable African affinity in the Lepidoptera has been mentioned to me by Dr. Welwitsch. It is plain that an affinity to any genus endowed with peculiar pro. perties is rendered doubly certain if the supposed allied species possesses the same properties. There is a Lepidopterous insect in Australia, the larva of which possesses remarkable poisonous powers. It has been named Dorato. phora villnerans. Such insects also occur in South Africa. Livingstone speaks of a caterpillar called Rigura as producing fearful agony if a sore is touched with its entrails. Mr. Baynes, in his "Explorations in South-west Africa," speaks of another, or perhaps the same, which he calls the $K a a$, and which is used as a poison for their arrows by the Bushmen; and Dr. Welwitsch had a personal experience of the severe swclling and pain in every part of his body which he touched with his hand after collecting specimens of a caterpillar against which he had been warned as poisonous. He had in consequence of the warning carefully avoided touching them, shoving them into a phial with a straw; but whether he had inadvertently touched them or fingered the leaves on which they had been feeding (which he collected for examination), he and his servant were both laid up helpless for two or three days. His specimens of the caterpillar were lost; but among his Lepidoptera Dr. Fendler of Vienna, who has undertaken a description of them, finds no less than four species of Doratophora, and these, doubtless, are the perfect insects of species of the caterpillar, from one of which he suffered."

The second passage which I wish to quote is from a paper by Mr. Roland Trimen, Notes on the above paper, and also published in the Linnean Society's journal. It is as follows :-

"At p. 55 Mr. Murray notes what he considers ' a very 
remarkable African affinity' in the Lepidoptera of Aus. tralia, in reference to the case of the larva of Doratophora vulnerans Lewin. The instances which he cites as analogous, however, are very different in character, for he quotes the mention by Livingstone ' of a caterpillar called Rigura, producing fearful agony if a sore is touched with its entrails'; and the statement made by Baynes and other travellers, that a caterpillar is used by the Bushmen to poison their arrows. It is evident that, if a caterpillar be used at all for poisoning arrows (concerning which report my inquiries have hitherto been attended by no satisfactory result) it must be the intestines or juices of the animal which are so employed. But the case of Doratifera vulnerans is the common one of (what appears to be mechanical) irritation, by means of clusters of spines, a defence possessed by many caterpillars, not only in Australia and South Africa, but throughout the globe, and of which the larva of the European Cuthocampa processionca presents a familiar example. Duncan (Nat. Libr. Ent. vol. vii. Exotic Moths, pp. I \&I-2. pl. xxii. f. 5) represents the larva of $D$. vulnerrans as possessing four fascicles of rufous spines, exsertile at will on both the anterior and posterior portions of the body, and quotes Lewin to the effect that the wound inflicted by the fascicles is very painful. According to. Mr. Murray's account it would appear that the African larvx, from the handling of which Dr. Welwitsch expcrienced such suffering, were near allies (if not actually species of Doratifera); and the con. clusion is obvious that it was by fascicles of spines that the pain was occasioned-not an uncommon case in the warmer parts of the world, and one by no means indicative of any special relation between the Lepidopterous faunas of South Africa and Australia."

$\mathrm{Mr}$. Trimen is obviously right as to the absence of analogy between the venomous properties of the cater. pillars spoken of by Livingstone and Baynes, and those met with by Dr. Welwitsch, and it was a slip on my part to collocate them together; but I am not satisfied that he is equally right in referring the pain caused by the species of Doralophora to mechanical irritation. He gives no facts in support of his assumption to that effect, and the facts communicated to me by Dr. Welwitsch regarding the insect from which he suffered scem to me wholly inconsistent with that supposition. It may be supposed from his and my silence that we acquiesed in $\mathrm{Mr}$. Trimen's views. But it is not so. IVhen Mr. Trimen's paper appeared Dr. Welwitsch spoke to me upon the point, and I urged him to communicate to the scientific world fuller details of the incident than I had given, and I understood that he intended to do so in any account of the insects collected by him. I therefore did not feel warranted in speaking, which I now regrct, for as with much else that he had on hand to do, his life has been too short for him to do it himself. Now that he has passed away from us I should not like an erroneous impression to exist as to the facts; and although I have little to add to what I formerly stated as communicated by him to me, I should wish to repeat it more precisely, and to say that Dr. Welwitsch himself was firmly convinced that it was not a case of mechanical irritation but of a special virus of unusual potency.

In the first place, then, Dr. Welwitsch had heard of this noxious caterpillar before he met with it-the natives knew it well and dreaded it. In the next place when he did meet with it his native attendant warned him of itand they took every precaution against touching it ; they plucked leaves on which the caterpillars were feeding and giided them from the leaf into the wide-mouthed bottle or vessel he had to carry such specimens home in. They also took specimens of the plant on which they were feeding. I suggested to him that the sting might have been in the plant, but this he was positive was not the case. The virulence of the venom was such that by the time they reached home in an hour or so after, every tender part of their body which they had touched with their tingers had become swollen and inflamed; their eyes were closed up, their lips and cheeks swollen as if they had been assisting (as principals) at a prize fight, and the consequent fever was so great that they were laid up, unable to move for two or three days; and when they did get up he found that their attendants had bundled out of the house both the caterpillars and the plants on which they fed. Now it seems to me that mechanical irritation is a wholly inadequate cause for such extreme inflammatory action. Mechanical irritation may go a certain length, but there are bounds beyond which we must look for some other explanation.

But first we want more facts and more examples. I exhibit two caterpillars, apparently different species, which I have received from Old Calabar, given to me with a notandum as reckoned injurious if not venomous, but my information as to them is too vague to allow me to cite them as positive examples of venomous caterpillars. And I also show one from Brazil which I have received from my friend, Mr. Fry, which he informs me bears a very bad character in Brazil. Both of these, indeed, all to which this property has been ascribed, are hairy caterpillars; but then it is onlyinairy caterpillars that seem to have the necessary apparatus for stinging-all stinging plants, so far as I know, are hairy. If the caterpillars have a special venom, then, as in the nettle, there should be a gland at the base of each hair, which should be hollow, and the spines in most, if not all, our caterpillars are hollow. I know of no physiological reason against their being so made. In the skin of the newt there are pores which exude an acrid irritating fluid. If a hollow hair were placed over the pore with proper muscles, we should then have a parallel to the supposed case.

But, as I saf before, we want information as to the existence and amount of this venomous property, and the chief object of this paper to-night is, after eliciting the views of the meeting, to suggest to those who may have the opportunity, the desirableness of making observations on the point.

A. Murray

\section{ON SPACE OF FOUR DIMENSIONS}

$W^{E}$ may define space as that which indicates and measures the extension of the Universe. We may determine the form and position of any material object by assuming three infinite planes, fixed in infinite space, and at right angles to each other. Space then is the room occupied by matter, or included between distant masses of matter; and, as such, we know of it only as possessing three dimensions:-length, breadth, thick-
ness.

Descales (Principia pars. 2, "Quid sit spatium, sizle locus internu(") remarks, "For, in truth, the same extension in length, breadth, and depth, which constitutes space, constituted body; and the difference between them consists only in this: that in body we consider extension as particular, and conceive it to change with the body; whereas in space we attribute to extension a generic unity (genericam unitatem), thus after taking from a certain space the body which occupied it, we do not suppose that we have at the same time removed the extension of the space, because it appears to us that the same extension remains there so long as it is of the same magnitude and figure, and preserves the same situation in respect to certain bodies around it, by means of which we determine the space."

Gauss used to say that one of the happinesses of his future life would be the amplification of his conceptions of space; the realisation of that which he had once known as space of three dimensions, as space of four dimensions. For just as we can conceive of beings "like infinitely attenuated book-worms in an infinitely thin 